\title{
Determinants of Severe Acute Malnutrition Among Children 6-36 Months in Kalafo District, Riverine Context, Ethiopia. Unmatched Case Control With Qualitative Study.
}

Ahmed Tahir Ahmed ( $\square$ ahmedpublic1@gmail.com )

Jigjiga University https://orcid.org/0000-0002-6468-6369

Abdifatah Elmi

JJU: Jigjiga University

Abdulahi Abas

Jigjiga University

Abdilahi Omer

Jigjiga University

Research

Keywords: Severe Acute Malnutrition, Determinants, Riverine area, Ethiopia

Posted Date: December 18th, 2020

DOl: https://doi.org/10.21203/rs.3.rs-130197/v1

License: (c) (i) This work is licensed under a Creative Commons Attribution 4.0 International License.

Read Full License 


\section{Determinants of Severe Acute Malnutrition among children 6-36 months in Kalafo district, Riverine context, Ethiopia. Unmatched case control.}

Ahmed Tahir Ahmed ${ }^{1} ;$ Abdulahi Abas $^{1} ;$ Abdifatah Elmi $^{1}$ and Abdilahi Omer ${ }^{1}$

${ }^{1}$ Public Health, College of medicine and Health science, Jigjiga University, Somali, Ethiopia

Correspondence Author: [Ahmed Tahir Ahmed]

P.O.Box: 1020, Public health department, College of medicine and health science, Jigjiga University, Ethiopia.

Tel [+251910586052] Email : [ahmedpublic1@gmail.com] or [Ahmedtahir@jju.edu.et]

\section{Abstract}

Background: Malnutrition remains prevalent and existing health problem globally. Particularly Undernutrition is a major public health issue in developing countries. Globally the causes of severe acute undernutrition varies across context. The aim of this study was to identify the determinants of severe acute malnutrition to uncover contextual factors based on UNICEF conceptual framework, as there was no study done in a similar context in Ethiopia.

Methods: Health facility based (health post) un-matched case control study with Key informant interview was conducted to identify determinant factors of severe acute malnutrition(SAM) among children between 6 to 36 months. 246 children( 82 cases and 164) with their mothers or care takers participated the study which was conducted between December 20, 2019 to January 20, 2020 in Kalafo district in Shebele River. Odds ratio with 95\% confidence interval was calculated to identify the determinants of SAM among children aged 6-36 months using multivariate logistic regression.

Results: The Odds of Severe Acute Malnutrition was 2.28(1.22,4.26); 4.68(2.29,9.58); $2.85(1.26,6.45) ; 2.39(1.16,4.96)$ and $3.262(1.46,7.31)$ and $3.237(1.45,7.23)$; respectively for mothers with three or more under five children, Children with inadequate dietary diversity, experienced diarrhea in past two weeks, their mothers had not nutrition counselling during pregnancy, Children's age between 6-11 and 12-17 months as compared to controls.

Conclusion The finding of this study reveals that the main determinants of severe acute malnutrition in riverine context are multi-level. On top of poor childcare and polygamy in qualitative finding, Diarrhea and inadequate dietary intake under the category of immediate cause of malnutrition. Having more than ( $\geq 3)$ under-five children, young age (6-11 and $12-17$ months) and not having nutrition counseling during pregnancy were also among basic determinants of severe acute malnutrition in riverine context. Decisive and multi-sectoral approach is required to addressing SAM in the riverine area. Keywords: Severe Acute Malnutrition, Determinants, Riverine area, Ethiopia. 


\section{Background}

Malnutrition remains prevalent and existing health problem globally. ${ }^{1,2,3}$ Particularly Undernutrition is a major public health issue in developing countries. ${ }^{2,4,5,6}$ Across regions there are huge disparities regarding undernutrition. South Asia (35.8\% and east Africa $(34.4 \%)$ shows exceedingly higher stunting rate than global average $(22.9 \%){ }^{2}$

The trends of acute malnutrition (Wasting) remains the same over decades in Kenya and Zambia ${ }^{7}$. Despite national nutrition commitments, undernutrition among under-five children is a formidable challenge in Ethiopia too, ${ }^{8,9,10}$ particularly in Somali region where wasting (22.7\%) and anemia $(83 \%)$ among under five children is profoundly higher than national average. ${ }^{8,9,11}$ Recently, Somali region shared the highest (26\%) severe acute malnutrition burden in the country. ${ }^{11}$

Globally the causes of acute undernutrition are too many and varies across context. Exhaustive identification of such broad multi-sectoral factors will lead comprehensive intervention. Many studies in developing countries including Ethiopia showed that household characteristics like income, ${ }^{9,1213,14,15}$ less access to health service, ${ }^{12,14}$ household head, ${ }^{12,13,14}$ lack of toilet, ${ }^{16,17}$ mothers education, ${ }^{18,19,20}$ paternal education, ${ }^{21}$ handwashing, ${ }^{22,23,24}$ household food insecurity, ${ }^{23,24}$ poor exclusive breast feeding, ${ }^{25,22,26}$ and number of under-five children or family size ${ }^{22,27,28}$ has explained the occurrence of acute malnutrition.

Moreover, many more factors like post-natal vitamin A supplementation, ${ }^{9,}, 23$ acute infections like diarrhea and malaria, ${ }^{19,29,30,31,32}$ child spacing, ${ }^{12,} 15$ maternal knowledge and awareness about infant and young child feeding, ${ }^{33}$ iodized salt use,${ }^{30}$ water sources, ${ }^{30}$ low birth weight, ${ }^{22}$ birth order, ${ }^{34}$ bottle feeding, ${ }^{15,16}$ inappropriate initiation time of complementary feeding, ${ }^{31}$ age of the child, ${ }^{26,28,31}$ and low $(<45 \mathrm{~kg})$ maternal weight ${ }^{22}$ are also behind the occurrence of acute malnutrition. The other important determinant of acute malnutrition were male sex ${ }^{23,32,34,35}$ and inadequate dietary diversity of the child ${ }^{30,35}$ Likewise, recent studies indicate that feeding practice, maternal age and nutrition counseling during pregnancy were significantly associated with acute malnutrition among under-five children. ${ }^{15,16,20,23}$ However, un-intended pregnancy increases the odds of chronic undernutrition (stunting) among under-five children. ${ }^{36}$ Whereas; fathers and mothers literacy, and higher wealth index decrease the odds of under-nutrition among under-five children. ${ }^{10,36,}$

The trends of severe acute malnutrition in Kalafo district of Shebele zone remains high according to the routine therapeutic feeding program reports (TFP). The number of TFP admissions in Kalafo district was two times higher compared to Mustahil district-an adjacent woreda with the 
same livelihood zone according to 2019 unpublished save the children report. Moreover, unpublished SMART survey conducted in Kalafo district, April 2018 shows high (16\%) GAM rate. This shows addressing only food insecurity will not guarantee addressing malnutrition in this area. The aim of this study was to assess the determinants of severe acute malnutrition among children aged 6 to 36 months in riverine district of Ethiopia. This made necessary to investigate the determinants of severe acute malnutrition to uncover contextual factors based on UNICEF conceptual framework of determinants of undernutrition (Fig.1).

\section{Methodology}

\section{Study area}

Kalafo Woreda/district is located and bounded between $655,013 \mathrm{~m}$ to $541,626 \mathrm{~m}$ north and $463,291 \mathrm{~m}$ to $369,612 \mathrm{~m}$ east (Fig.2). It is found in Shabele zone of the Somali regional state covering a total area of $6,494.54$ square Kilometer.

Kelafo woreda is located approximately $90 \mathrm{~km}$ southeast of the urban town Gode. It includes 15 kebeles made up of $180+$ sub-kebeles and the estimated population is 154000 . It has five Government run health centers.

The livelihood zone of Kalafo district is riverine area and its only source of water is the river. However, according to Somali region's Emergency Nutrition and Coordination Unit (ENCU) reports (unpublished routine data) showed high and persistent trends of acute under nutrition despite regular interventions by different humanitarian organizations and government. The reason behind this remains unknown.

\section{Study design}

Health facility based (health post) un-matched case control with qualitative study was done to identify determinant factors of severe acute malnutrition among children between 6 to 36 months.

\section{Study Population}

Children between 6 to 36 months in selected five health posts (HPs) of Kalafo district were study population

Selection of Cases: Children between 6 to 36 months with MUAC less than $11.5 \mathrm{~cm}$

Control: Children between 6 to 36 months with MUAC $\geq 12.5 \mathrm{~cm}$

\section{Study period}

The study was conducted between December 2019 and January 2020. 


\section{Study participants, Sample size and Sampling procedure}

Children with their mothers or caretakers who visited five randomly selected HPs with OTP service in Kalafo district were our study participants.

The number of cases and controls required for the study were determined using EpiInfo version 3.5.4 StatCalc with 95\% CL, 80\% power, 1:2 case to control ratio and expected frequency of exposure in control group of $33.43 \%$, to be able to detect a 2.24 Odds ratio. The $33.43 \%$ exposure in control group was based on use of toilet facility as a determinant of infant nutritional status conducted in Dabat district, North Gondar, Ethiopia ${ }^{16 .}$ A total 246 children aged 6 to 36 months (82 cases, and 164 controls; 1:2 ratio) were studied.

Regarding sampling procedure, from $32 \mathrm{HPs}$ in Kalafo district, 27 functional HPs with OTP service were selected. Among the 27 functional HPs, only five HPs (Kalaman, Dariko, Helobacad, Bargun, and Allow-Igadsii) were randomly selected for the study and the calculated sample size were allocated proportionally to the selected HPs based on their catchment under-five populations.

For qualitative part, key informant interview (KII) were conducted purposively on different individuals. The KIls were HEWs, district nutrition focal person and nutrition working partners. The sample size of KII was determined by data saturation.

Inclusion criteria: children aged 6 to 36 months who attended selected OTP sites for nutrition and health services, and lived in the study area for at least past six months prior the survey.

Exclusion criteria: Children with known diseases like Tuberculosis and Malaria were excluded from the study.

\section{Operational definition}

Adequate dietary diversity is when children received at least four food groups out of seven in the preceding 24 hours of the interview. ${ }^{37}$

Household food security is any household whose summations of Household Food Insecurity Access Scale (HFIAS) questions were $\leq 1$ point out of 27 scores $^{39}$

Household food insecurity is any household whose summations of Household Food Insecurity Access Scale (HFIAS) questions were $\geq 2$ points out of 27 scores. $^{39}$

Case: any child with MUAC $<11.5 \mathrm{~cm}$ (severe acute malnutrition) and/or presence of bilateral edema. ${ }^{40}$

Control: any child with MUAC $\geq 12.5 \mathrm{~cm}$ and/or with no bilateral edema. ${ }^{40}$ 


\section{Study variables}

The outcome of this study was severe acute malnutrition among children aged 6 to 36 months and categorized into case (severe acute malnutrition) and control. The study considered sociodemographic status, demographic data, household structure, household hygiene/sanitation and maternal and child characteristics like feeding practices, presence of disease, health service utilization, and household food security as an independent variables.

\section{Data collection methods}

Data on risk factor survey was conducted using standardized questionnaire (translated to Somali and back translation in to English) adapted from Conceptual framework of determinants of undernutrition (UNICEF, 2013) and other local studies on determinants of acute malnutrition ${ }^{19,24}$,

32 to provide risk factor prevalence in the study area. Trained health extension workers and nurses who were working in each selected health posts were collected data under strict supervision.

Diarrhea was determined when the child had three or more loose or watery stool in a 24-hour's period within the two weeks prior to the survey and this was assessed by asking the mothers or care takers. ${ }^{28}$

To assess dietary diversity practice, the sum of the number of different food groups consumed by the child in the 24 hours prior to the survey were asked the mother or caretaker. The list of food groups were, grains, roots, and tubers; legumes and nuts; dairy products (milk, yogurt, cheese); flesh foods (meat, fish, poultry and liver/organ meats); eggs; vitamin-A rich fruits and vegetables and other fruits and vegetables. The respondents whose children consumed four or more of these food groups were labelled as having adequate dietary diversity and inadequate otherwise. ${ }^{37}$ The nine standard Household Food Insecurity Access Scale (HFIAS) questions developed by Food and Nutrition Technical Assistance (FANTA) in 2007 was used to determine food security status of the households. The frequency-of-occurrence question was not asked the respondents if the corresponding frequency question did not happen in the last four weeks (30 days). Food secure individuals were those who did not experience any yes response or rarely experienced worry, whilst all the rest responses were categorized food insecure. Food security index was produced for further analysis.

For qualitative part, KIls were conducted using checklist extracted from UNICEF conceptual framework by experienced health workers familiar with local language and context. Local (Somali) language and tape record was used in all interviews. 


\section{Anthropometric measurement}

Nutritional status of the child was assessed by using MUAC tape on midway between the olecranon and acromion process. The tape was comfortably positioned at the midpoint according to the standard and was checked as not pulled too tight or too loose while recorded to the nearest $0.1 \mathrm{~cm}$. To assess Edema, thumbs were pressed gently on feet of each selected child bilaterally for three seconds (count of 101, 102, and 103). As per the standard when released pressing, records was made as "normal”, "+", “++", and "+++" if no pitting, pitting on feet, feet plus legs and feet plus hands and face respectively.

\section{Data Management and Analysis.}

Kobo toolbox was used for data entry and collection. Data was cleaned using Kobo toolbox and analyzed in SPSS version 20.

Bivariate and multivariable binary logistic regression was employed to identify predictors Of severe acute malnutrition. Variables with $\mathrm{P}$ - value less than 0.25 in bivariate analysis and other important determinant of acute malnutrition were considered to Multivariate analysis. Whilst; variables with P-value less than 0.05 were declared significant association with outcome variable in multivariate binary logistic regression analysis. Lastly, Strength of association was determined using the odds ratio with $95 \% \mathrm{Cl}$, backward logistic regression method and Hosmer Lemeshow test for model goodness of fit.

For qualitative data, it was transcribed manually and triangulated for better understanding about severe acute determinants.

\section{Result}

\section{Maternal and child characteristics}

This study included 246 children aged 6-36 months of which 82 and 164 were cases and controls respectively. Among children, two of them had bilateral edema on feet whilst the rest had no edema. The mean age and standard deviation of cases and controls were $15.23 \pm 7$ and 19.6 \pm 8.96 respectively. A small number of $(19.5 \%)$ cases were older than 23 months compared to 
controls $(40.2 \%)$. Likewise, More $(63.4 \%)$ of cases' mothers had three or more under five aged children compared to controls (44.5\%).

However, mothers' literacy and occupation and child's sex among cases were almost comparable to controls (table1).

Moreover, more children (39\%) among cases had inadequate dietary diversity practices compared to controls (14\%). whilst, food insecurity of cases $(35.4 \%)$ were comparable to controls (38.4\%). Among cases, only (69.5\%) were using treated water compared to controls $(79.3 \%)$. Controls' mothers and children had received better (79.3\%) nutrition counseling during ANC and higher $(67.1 \%)$ vaccine coverage than cases' mothers $(69.5 \%)$ and children $(56.1 \%)$ respectively. (Table 2).

Cases in age category of 6-11, 12-17 months had more odds (3.12(1.49,6.51),3.63(1.73,7.59) of being SAM compared to controls and cases whose mothers had three or more under-five children were more likely to have become SAM $(2.16(1.25,3.73))$ as opposed to controls(Table 1$)$.

Children with inadequate dietary diversity, experienced diarrhea in past two weeks, used untreated water, being $2^{\text {th }}$ to $5^{\text {th }}$ child order, not fully vaccinated and whose mothers had not received nutrition counselling during ANC were more likely to be severe acutely malnourished(Cases) with odds ratio of $3.92(2.09,7.33), 2.36(1.15,4.87), 1.67(0.92,3.06)$, 1.84(1.03,3.28), 1.59(0.92,2.75) and 1.67(0.92, 3.06) compared to controls(Table 2).

\section{Determinants of severe acute malnutrition among children aged 6 to 36 months in Kalafo district, Ethiopia.}

Variables considered into multivariate logistic regression model were all those with P-value < 0.25 on bivariate analysis. In addition to this, exclusive breastfeeding and male sex variables were also considered the final model analysis regardless of its $\mathrm{P}$-value due to its importance in the literature. The model of goodness of fit was tested, $X^{2}(8, n=246)=8.747, P$-value $=0.364$. The odds of being severe acute malnutrition (cases) were almost 3 times higher among children experienced diarrhea two weeks preceding the study $\mathrm{AOR}=2.85(1.26,6.45) ; 4.7$ times among children eaten inadequate dietary diversity $\mathrm{AOR}=4.68(2.29,9.58) ; 2.4$ higher among children whose their mothers did not get nutrition counseling during $A N C$ visits $A O R=2.39(1.16,4.96)$; 2.3 higher among children from households with more than three $(\geq 3)$ under-five children, $A O R=$ 2.28(1.22,4.26); and 3 times higher among children aged 6-11 and 12-17 months respectively; compared to controls( Table 3).

\section{Qualitative result}


In total, five KIls were conducted; two HEWs KIIs, 2 active nutrition-working partners KIls and one District nutrition focal person KII to deeply understand better the determinants of severe acute malnutrition in riverine context.

Qualitative study result showed a consistent finding with some identified significant determinants but not all. In general, qualitative study identified the following factors as a SAM determinant: contaminated water, Diarrhea, Polygamy, too number of children, farm chore and poor riverine communities.

"To my experience, SAM is common across children around the river (Negro) simply because they come across frequent diarrhea that resulted from drinking unclean river water. At the same time, Most of the mothers are farm daily labors and they may not have a time to take care their children. Therefore, I do give RUTF again to children who were successfully recovered from severe acute malnutrition previously". HEW KII, Dariko HP.

In addition to this, "mothers in this area experience many children exceptionally and no mother takes family planning." HEW KII, Kalaman HP.

"The people around this river do marry more than one wife and have many children from each wife and yet they do not have income to support, as they are farm daily laborers. Shebele River inhabitants (Negro) are not the farm owners but are daily workers." Kalafo district Nutrition focal person KII.

"Previously there were many non-governmental organizations supporting the emergency nutrition sector. However; currently we are only one supporting and it is out of our capacity as severe acute malnutrition among children is continuously high across a year." The cause of SAM in this area are many and main ones are diarrhea and lack of care. OTP Nurse, Save the children KII.

Table 1. Bivariate analysis of Socio-demographic characteristics of the study participants and nutritional status, Kalafo district, east Ethiopia, 2020( $n=246$ ). 


\begin{tabular}{|c|c|c|c|c|}
\hline \multirow{2}{*}{$\begin{array}{l}\text { Characteristics } \\
\text { Age }\end{array}$} & \multicolumn{2}{|c|}{ Nutrition status } & \multirow[t]{2}{*}{ COR } & \multirow[t]{2}{*}{ P-Value } \\
\hline & $\begin{array}{l}\text { Case }(\%) \\
n=82\end{array}$ & $\begin{array}{l}\text { Control (\%), } \\
n=164\end{array}$ & & \\
\hline $6-11$ & $28(34.1)$ & $37(22.6)$ & $3.12(1.49,6.51)$ & 0.002 \\
\hline $12-17$ & $29(35.4)$ & $33(20.1)$ & $3.63(1.73,7.59)$ & 0.001 \\
\hline $18-23$ & $9(11.0)$ & $28(17.1)$ & $1.33(0.52,3.35)$ & 0.552 \\
\hline$>23$ & $16(19.5)$ & $66(40.2)$ & & \\
\hline $\begin{array}{l}\text { Mean age ( } \pm \text { standard } \\
\text { deviation) }\end{array}$ & $15.23( \pm 7)$ & $\begin{array}{l}19.6( \pm \\
8.96)\end{array}$ & & \\
\hline \multicolumn{5}{|l|}{ Maternal education } \\
\hline Unable & $65(79.3)$ & $123(75.0)$ & $1.27(0.67,2.42)$ & 0.458 \\
\hline Able & $17(20.7)$ & $41(25)$ & 1 & \\
\hline \multicolumn{5}{|l|}{ Maternal occupation } \\
\hline Farmer & $44(53.7)$ & $86(52.4)$ & $1.53(0.15,15.19)$ & 0.71 \\
\hline House wife & $37(45.1)$ & $75(45.7)$ & $1.480(0.15,14,72)$ & 0.74 \\
\hline Government worker & $1(1.2)$ & $3(1.8)$ & 1 & \\
\hline \multicolumn{5}{|l|}{ \# of under-five child } \\
\hline$<3$ children & $30(36.6)$ & $91(55.5)$ & 1 & \\
\hline$>$ or $=3$ children & $52(63.4)$ & $73(44.5)$ & $2.16(1.25,3.73)$ & $0.006^{*}$ \\
\hline \multicolumn{5}{|l|}{ Sex of the child } \\
\hline Male & $42(51.2)$ & $89(54.3)$ & 1 & \\
\hline Female & $40(48.8)$ & $75(45.7)$ & $1.13(0.66,1.92)$ & 0.65 \\
\hline
\end{tabular}


Table 2. Bivariate analysis of selected characteristics of study participants in Kalafo district, Eastern Ethiopia $(\mathrm{n}=246)$.

\begin{tabular}{|c|c|c|c|c|}
\hline Characteristics & $\begin{array}{l}\text { Nutrition } \\
\text { status }\end{array}$ & COR & P-Value & \\
\hline \multicolumn{5}{|l|}{ Birth order } \\
\hline first & 11(13.4) & $24(14.6)$ & $1.19(0.53,2.68)$ & 0.682 \\
\hline second and fifth & $37(45.1)$ & $52(31.7)$ & $1.84(1.03,3.28)$ & $0.038^{*}$ \\
\hline Above fifth & $34(41.5)$ & $88(53.7)$ & 1 & \\
\hline \multicolumn{5}{|l|}{ Birth interval } \\
\hline$\geq 2$ years & $17(20.7)$ & $45(27.4)$ & 1 & \\
\hline$<2$ years & $11965(79.3)$ & $119(72.6)$ & $1.45(0.76,2.73)$ & 0.25 \\
\hline \multicolumn{5}{|l|}{ Do you have latrine } \\
\hline No & $4726(31.7)$ & $47(28.7)$ & & \\
\hline Yes & $11756(68.3)$ & $117(71.3)$ & $1.15(0.65,2.05)$ & 0.622 \\
\hline \multicolumn{5}{|l|}{ Do you treat your water } \\
\hline No & $25(30.5)$ & $34(20.7)$ & $1.67(0.92,3.06)$ & 0.093 \\
\hline Yes & $57(69.5)$ & $130(79.3)$ & 1 & \\
\hline \multicolumn{5}{|c|}{ How often do you stay your child? } \\
\hline Rarely & $30(36.6)$ & $72(43.9)$ & $0.74(0.43,1.27)$ & 0.273 \\
\hline Always/sometimes & $52(63.4)$ & $92(56.1)$ & 1 & \\
\hline \multicolumn{5}{|c|}{$\begin{array}{l}\text { Do you have intention to use FP in } \\
\text { the future? }\end{array}$} \\
\hline No & $49(59.8)$ & $105(64.0)$ & $0.83(0.48,1.44)$ & 0.51 \\
\hline
\end{tabular}




\begin{tabular}{|c|c|c|c|c|}
\hline Yes & $33(40.2)$ & $59(36.0)$ & 1 & \\
\hline \multicolumn{5}{|l|}{ Are you currently pregnant? } \\
\hline Yes & $57(69.5)$ & $115(70.1)$ & $0.97(0.55,1.73)$ & 0.922 \\
\hline No & $25(30.5)$ & $49(29.9)$ & 1 & \\
\hline \multicolumn{5}{|l|}{ Dietary diversity score } \\
\hline adequate dietary diversity & $50(61.0)$ & $141(86.0)$ & 1 & \\
\hline inadequate dietary diversity & $32(39.0)$ & $23(14.0)$ & $3.92(2.09,7.33)$ & 0.000 \\
\hline \multicolumn{5}{|l|}{ Household food security score } \\
\hline Food secure & $53(64.6)$ & 101(61.6) & 1 & \\
\hline Food insecure & $29(35.4)$ & $63(38.4)$ & $1.14(0.66,1.98)$ & 0.641 \\
\hline $\begin{array}{l}\text { Have your child experienced } \\
\text { diarrhea during the past } 2 \text { weeks }\end{array}$ & $38.4 \%$ & $35.4 \%$ & & \\
\hline No & $11(13.4)$ & $44(26.8)$ & 1 & \\
\hline Yes & $71(86.6)$ & $120(73.2)$ & $2.36(1.15,4.87)$ & 0.02 \\
\hline \multicolumn{5}{|l|}{ Wash hands before eating } \\
\hline No & $18(22.0)$ & $31(18.9)$ & $1.21(0.63,2.32)$ & 0.573 \\
\hline Yes & $64(78.0)$ & $133(81.1)$ & 1 & \\
\hline \multicolumn{5}{|l|}{ Waste disposal } \\
\hline Proper & $82(100)$ & $151(92.1)$ & 1 & \\
\hline Improper & $0(0.0)$ & $13(7.9)$ & & \\
\hline \multicolumn{5}{|l|}{ Fully vaccinated child } \\
\hline No & $36(43.9)$ & $54(32.9)$ & $1.59(0.92,2.75)$ & 0.093 \\
\hline Yes & $46(56.1)$ & $110(67.1)$ & 1 & \\
\hline \multicolumn{5}{|l|}{ Child exclusive breast-feed. } \\
\hline No & $46(56.1)$ & $81(49.4)$ & $1.309(0.77,2.23)$ & 0.322 \\
\hline Yes & $36(43.9)$ & $83(50.6)$ & 1 & \\
\hline \multicolumn{5}{|l|}{$\begin{array}{l}\text { child receive vitamin A } \\
\text { supplementation in last } 6 \text { months }\end{array}$} \\
\hline No & $17(20.7)$ & $53(32.3)$ & $0.55(0.29,1.03)$ & 0.06 \\
\hline Yes & $65(79.3)$ & $111(67.7)$ & 1 & \\
\hline \multicolumn{5}{|l|}{ Nutrition counseling during ANC } \\
\hline No & $25(30.5)$ & $34(20.7)$ & $1.67(0.92,3.06)$ & 0.093 \\
\hline Yes & $57(69.5)$ & $130(79.3)$ & 1 & \\
\hline \multicolumn{5}{|l|}{ Nutrition counseling during PNC } \\
\hline No & $35(42.7)$ & $77(47.0)$ & $0.84(0.49,1.44)$ & 0.53 \\
\hline Yes & $47(57.3)$ & $87(53.0)$ & 1 & \\
\hline \multicolumn{5}{|l|}{ complementary Food demonstration } \\
\hline No & $35(42.7)$ & $65(39.6)$ & $1.13(0.66,1.94)$ & 0.646 \\
\hline Yes & $47(57.3)$ & $99(60.4)$ & 1 & \\
\hline Does HEW visit your home & & & & \\
\hline
\end{tabular}




\begin{tabular}{|c|l|l|l|l|}
\hline No & $18(22.0)$ & $27(16.5)$ & $1.43(0.73,2.78)$ & 0.295 \\
\hline Yes & $64(78.0)$ & $137(83.5)$ & 1 & \\
\hline & & & & \\
\hline
\end{tabular}

Table 3. Determinants of acute malnutrition among children aged 6 to 36 months in Kalafo district, Somali region, Ethiopia, $2020(\mathrm{n}=246)$

\begin{tabular}{|c|c|c|c|c|c|c|}
\hline \multirow{2}{*}{$\begin{array}{l}\text { Characteristics } \\
\text { Age }\end{array}$} & \multicolumn{2}{|c|}{ Nutrition status } & \multirow[t]{2}{*}{ COR } & \multirow[t]{2}{*}{ P-Value } & \multirow[t]{2}{*}{ AOR } & \multirow[t]{2}{*}{$p$-value } \\
\hline & $\begin{array}{l}\text { Case (\%) } \\
\mathrm{n}=82\end{array}$ & $\begin{array}{l}\text { Control } \\
(\%) \\
n=164\end{array}$ & & & & \\
\hline $6-11$ & $28(34.1)$ & $37(22.6)$ & & 0.002 & $3.262(1.46,7.31)$ & .004 \\
\hline $12-17$ & $29(35.4)$ & $33(20.1)$ & & 0.001 & $3.237(1.45,7.23)$ & .004 \\
\hline $18-23$ & $9(11.0)$ & $28(17.1)$ & & 0.552 & $0.79(0.28,2.21)$ & .660 \\
\hline$>23$ & $16(19.5)$ & $66(40.2)$ & 1 & 1 & & \\
\hline \multicolumn{7}{|l|}{$\begin{array}{l}\text { Have your child } \\
\text { experienced diarrhea } \\
\text { during the past } 2 \\
\text { weeks }\end{array}$} \\
\hline No & 11(13.4) & $44(26.8)$ & 1 & & & \\
\hline Yes & $71(86.6)$ & $120(73.2)$ & $2.36(1.15,4.87)$ & 0.02 & $2.85(1.26,6.45)$ & .012 \\
\hline \multicolumn{7}{|l|}{$\begin{array}{l}\text { Dietary diversity } \\
\text { score }\end{array}$} \\
\hline $\begin{array}{l}\text { adequate dietary } \\
\text { diversity }\end{array}$ & $50(61.0)$ & $141(86.0)$ & 1 & & & \\
\hline $\begin{array}{l}\text { inadequate dietary } \\
\text { diversity }\end{array}$ & $32(39.0)$ & $23(14.0)$ & $3.92(2.09,7.33)$ & 0.000 & $4.68(2.29,9.58)$ & $\begin{array}{l}<0.00 \\
1\end{array}$ \\
\hline \multicolumn{7}{|l|}{$\begin{array}{l}\text { Nutrition counseling } \\
\text { during ANC }\end{array}$} \\
\hline No & $25(30.5)$ & $34(20.7)$ & $\begin{array}{l}1.67(0.92 \\
3.06)\end{array}$ & 0.093 & $2.39(1.16,4.96)$ & 0.018 \\
\hline Yes & $57(69.5)$ & $130(79.3)$ & 1 & & & \\
\hline \multicolumn{7}{|l|}{ \# of under-five child } \\
\hline$<3$ children & $30(36.6)$ & $91(55.5)$ & 1 & & & \\
\hline$>$ or $=3$ children & $52(63.4)$ & $73(44.5)$ & $2.16(1.25,3.73)$ & $0.006^{*}$ & $2.28(1.22,4.26)$ & .010 \\
\hline \multicolumn{7}{|l|}{ Sex of the child } \\
\hline Male & $42(51.2)$ & $89(54.3)$ & 1 & & 1 & \\
\hline Female & $40(48.8)$ & $75(45.7)$ & $1.13(0.66,1.92$ & 0.65 & - & - \\
\hline
\end{tabular}




\begin{tabular}{|c|c|c|c|c|c|c|}
\hline $\begin{array}{l}\text { Child exclusive } \\
\text { breast-feed. }\end{array}$ & & & & & & \\
\hline No & $46(56.1)$ & $81(49.4)$ & $\begin{array}{l}\text { 1.309(0.77,2.2 } \\
3)\end{array}$ & 0.322 & - & - \\
\hline Yes & $36(43.9)$ & $83(50.6)$ & 1 & & 1 & \\
\hline \multicolumn{7}{|l|}{ Birth order } \\
\hline first & $11(13.4)$ & $24(14.6)$ & $1.19(0.53,2.68)$ & 0.682 & - & - \\
\hline second and fifth & $37(45.1)$ & $52(31.7)$ & $1.84(1.03,3.28)$ & $0.038^{*}$ & - & - \\
\hline Above fifth & $34(41.5)$ & $88(53.7)$ & 1 & & 1 & \\
\hline \multicolumn{7}{|l|}{$\begin{array}{l}\text { Do you treat your } \\
\text { water }\end{array}$} \\
\hline No & $25(30.5)$ & $34(20.7)$ & $1.67(0.92,3.06)$ & 0.093 & - & - \\
\hline Yes & $57(69.5)$ & $130(79.3)$ & 1 & & 1 & \\
\hline \multicolumn{7}{|l|}{$\begin{array}{l}\text { Fully vaccinated } \\
\text { child }\end{array}$} \\
\hline No & $36(43.9)$ & $54(32.9)$ & $1.59(0.92,2.75)$ & 0.093 & - & - \\
\hline Yes & $46(56.1)$ & $110(67.1)$ & 1 & & 1 & \\
\hline
\end{tabular}

\section{Discussion}

This quantitative study found that five factors were determining the severe acute malnutrition among children aged 6-36 months in riverine context. These were age group (6-11 and 1217 months), inadequate dietary practices, and experienced diarrhea within two weeks preceding the data collection, from household with three and more under-five children and not exposed to nutrition counseling during ANC visits. However, poor childcare and polygamy are determinants of SAM in qualitative findings.

The odds of being severe acute malnutrition were higher among younger children aged 6-11 and 12-17 months compared to older children (18-23 and > 23 months). This finding is in line with studies done in Ethiopia, ${ }^{21,26,28,31}$ Niger, ${ }^{19}$ and Ghana. ${ }^{34}$

The possible explanation is the fact that most children do not go smoothly the transition period (initiation of complementary feeding) in low-income countries due to many reasons.

The odds of being severe acute malnutrition were higher among children from households with three or more under-five children compared with children from households with less than three under-five children. This finding is consistent with studies done in India, ${ }^{22}$ Ethiopia, ${ }^{20,41,42}$ and report of Ethiopian DHS 2016. ${ }^{8}$ The finding of our study is also in agreement with studies done in Ethiopia $28,32,35$ which indicates larger family size ( $\geq 4$ or 5 ) was determining factor for wasting 
among under-five children. This might be due to households either with higher number of underfive children or larger family size increase chore on mothers, which compromise the care or feeding practices of their children. ${ }^{35}$ However, this finding is against a study done in Arizona, USA. ${ }^{27}$ This might be due to a difference in context, study design and outcome (SAM) of current study.

The current study shows that odds of being severe acute malnutrition were higher among children who had inadequate dietary diversity in past 24 hours preceding the data collection compared their counterparts. This finding is in line with studies done in India, ${ }^{22}$ Afghanistan ${ }^{30}$ and Ethiopia. ${ }^{9,35}$

However, it contradicts studies done in Cambodia, ${ }^{43}$ and Tanzania ${ }^{44}$ where inadequate dietary diversity was not associated with acute malnutrition of under-five children. The only possible explanation could be contextual factors that might determine acute malnutrition.

The current study also shows that odds of being severe acute malnutrition were higher among children who experienced diarrhea in past two weeks preceding the data collection compared their counterparts. This finding is in line with studies done in Afghanistan, ${ }^{30}$ Ethiopia ${ }^{31,18,26,32}$ and Niger. ${ }^{19}$ The possible explanation is acute diseases like diarrhea are immediate causes of acute malnutrition among children according to UNICEF conceptual framework.

Lastly, the odds of being severe acute malnutrition were higher among children whose mothers did not expose to nutrition counseling during ANC visits. This study is in line with studies done in Ethiopia. ${ }^{16,20}$ However, and study done in Pakistan ${ }^{38}$ shows counseling during ANC associated with stunting among under five children but not wasting. This might be due to different livelihood (riverine) of the current study and the fact that underlying factors (infant and young child feeding counseling) of undernutrition might not directly results acute malnutrition.

\section{Strengths and limitations}

The study is the first of its kind conducted in a riverine context to assess determinants of severe acute malnutrition among children aged 6-36 months. Programmers and policy makers can use this as an input in nutrition programs. Nevertheless, the study has limitations: important determinant variables like diarrhea, dietary practice, and food security were measured by asking respondents, which could expose social desirability and recall bias. Trained and experienced already assigned the HP were used to collect the data to manage possible weakness of the study. 


\title{
Conclusions
}

The finding of qualitative study shows poor childcare and polygamy were the determinants of SAM. However, according to quantitate study, the main determinants of severe acute malnutrition in riverine context were diarrhea and inadequate dietary intake under the category of immediate cause of malnutrition. Whilst higher $(\geq 3)$ number of under-five children were another important contextual determinant of severe acute malnutrition among children (6-36 months) in riverine zone of Somali region. Briefly, young age (6-11 and 12-17months) and not having nutrition counseling during pregnancy were also among distal determinants of severe acute malnutrition in riverine context.

\section{Recommendations}

Improvement has to be made on childcare giving practices including dietary diversity. Water treatment and family planning intervention should be integrated along with community-based management of severe acute malnutrition (CMAM) programs in riverine context.

\begin{abstract}
Abbreviations
CMAM, Community Based Management of Acute Malnutrition, ANC; Antenatal care, HP; health post, EDHS, Ethiopian Demographic and Health Survey; IFPRI, International food and policy research institute; DDS, dietary diversity score; FANTA, Food and Nutrition Technical Assistance; HFIAS, household food insecurity access scale; MUAC, mid upper arm circumference; SAM, severe acute malnutrition;
\end{abstract}

\section{Ethical approval}

Ethical approval was obtained from research ethical committee of Jigjiga University, Ethiopia. The objective and procedure of data collection was explained to study participants. The confidentiality and do no harm principles were respected across study period. Lastly, data was collected after oral informed consent was obtained from each participant.

\section{Availability of data and materials}

The datasets used and/or analyzed during the current study are available from the corresponding author on reasonable request.

\section{Competing interests}

The authors reports no conflicts of interest in this work

\section{Funding}


Jigjiga University has supported the data collection and supervision expenses. However, Jigjiga University has no any other contribution to this manuscript.

\section{Author contributions}

Ahmed Tahir has conceptualized, contributed concept, design, edit and drafted the manuscript. Abdifatah Elmi and Abdulahi Abas have revised and edited, whilst Abdilahi Omer has supervised and edited. All authors contributed the concept, analysis, and edition and approved.

\section{Acknowledgments}

We are grateful for mothers/caretaker who participated this study. We also thank data collectors, supervisors and Jigjiga University for their support during data collection.

\section{Authors' information}

Correspondence Author and two other authors(Elmi and i Abas) are assistant professors at Jigjiga University, Ethiopia. correspondence Author and i Abas are MPH in Nutrition with background of Nursing and Pharmacy respectively. Whilst Elmi and Omer are General MPH with public health background. Briefly, corresponding author and Elmi are both reviewers of international journal for equity in health.

\section{References}

1. Organization WH. UNICEF/WHO/The World Bank Group joint child malnutrition estimates: levels and trends in child malnutrition: key findings of the 2020 edition.

2. De Onis M, Borghi E, Arimond M, Webb P, Croft T, Saha K, et al. Prevalence thresholds for wasting, overweight and stunting in children under 5 years. Public health nutrition.2017, 22(1):175-9.

3. Institute IFPR. Global nutrition report: IFPRI. 2014;

4. Bhandari TR, Chhetri M. Nutritional status of under five year children and factors associated in Kapilvastu District, Nepal. J Nutr Health Food Sci. 2013; 1(1):1-6.

5. Organization WH. Pocket book of hospital care for children: guidelines for the management of common childhood illnesses: World Health Organization. 2013.

6. UNICEF. World Bank, UN Population Division: Levels and Trends in Child Mortality Reportâ€"Report 2012: Estimates Developed by The Inter-agency Group for Child Mortality Estimation. New York: UNICEF.

7. Hoffman D, Cacciola T, Barrios P, Simon J. Temporal changes and determinants of childhood nutritional status in Kenya and Zambia. Journal of Health, Population and Nutrition. 2017 Dec 1;36(1):27.

8. EDHS E. demographic and health survey 2016: key indicators report. The DHS Program ICF.363:364.

9. Tariku A, Bikis GA, Woldie H, Wassie MM, Worku AG. Child wasting is a severe public health problem in the predominantly rural population of Ethiopia: A community based crosssectional study. Archives of Public Health. 2017 Dec 1;75(1):26. 
10. Eshete H, Abebe $\mathrm{Y}$, Loha E, Gebru T, Tesheme T. Nutritional status and effect of maternal employment among children aged 6-59 months in Wolayta Sodo town, southern Ethiopia: a cross-sectional study. Ethiopian journal of health sciences. 2017;27(2):155-62.

\section{Unit, E..N.C. U., Cluster Nutrition Surveys since2000 - June 2014: Rural Woredas of} Ethiopia. 2014

12. Egata G, Berhane $Y$, Worku A. Predictors of acute undernutrition among children aged 6 to 36 months in east rural Ethiopia: a community based nested case-control study. BMC pediatrics. 2014 Dec 1;14(1):91.

13. Gelu A, Edris M, Derso T, Abebe Z. Undernutrition and associated factors among children aged 6-59 months living in slum areas of Gondar city, northwest Ethiopia: a cross-sectional study. Pediatric health, medicine and therapeutics. 2018;9:81.

14. Fentaw R, Bogale A, Abebaw D. Prevalence of child malnutrition in agro-pastoral households in Afar Regional State of Ethiopia. Nutrition Research and Practice. 2013 Apr $1 ; 7(2): 122-31$.

15. Pravana NK, Piryani S, Chaurasiya SP, et al (2017). Determinants of severe acute malnutrition among children under 5 years of age in Nepal: a community-based case-control study. BMJ Open; 7:e017084. doi:10.1136/ bmjopen-2017-017084

16. Wubante AA. Determinants of infant nutritional status in Dabat district, North Gondar, Ethiopia: a case control study. PloS one. 2017 Mar 27;12(3):e0174624.

17. Merel $\mathrm{H}$. van Cooten et al (2018). The association between acute malnutrition and water, sanitation, and hygiene among children aged 6-59 months in rural Ethiopia: wileyonlinelibrary.com/journal/mcn,MaternChildNutr.2019;15:e12631.https://doi.org/10.1111/mc n.12631

18. Gone T, Lemango F, Eliso E, Yohannes S, Yohannes T. The association between malaria and malnutrition among under-five children in Shashogo District, Southern Ethiopia: a casecontrol study. Infectious diseases of poverty. 2017 Dec 1;6(1):9.

19. Fava FP, Upton J, Banerjee RR, Taye M, Mude AG. Pre-feasibility study for Index-Based Livestock Insurance in Niger.

20. Gatjiek Tut and Dereje Tsegaye. Determinants of Acute Malnutrition Among Children Aged 6-59 Months Visiting Public Health Facilities in Gambella Town, Southwest Ethiopia Nutrition and Dietary Supplements: :12 147-156.

21. Seid A, Seyoum B, Mesfin F. Determinants of acute malnutrition among children aged 6-59 months in Public Health Facilities of Pastoralist Community, Afar Region, Northeast Ethiopia: a case control study. Journal of nutrition and metabolism. 2017 Jan 1;2017.

22. Ambadekar NN, Zodpey SP. Risk factors for severe acute malnutrition in under-five children: a case-control study in a rural part of India. Public health. 2017 Jan 1;142:136-43.

23. Abitew DB, et al (2020) Predictors of relapse of acute malnutrition following exit from community-based management program in Amhara region,Northwest Ethiopia: An unmatched case-control study.PLos-one 15(4): e0231524. https://doi.org/ 10.1371/journal.pone.0231524

24. Burza S, Mahajan R, Marino E, Sunyoto T, Shandilya C, Tabrez M, Kumar K, Jha A, Mathew $P$, Salse N, Casademont C. Seasonal effect and long-term nutritional status following exit from a 
community-based management of severe acute malnutrition program in Bihar, India. European journal of clinical nutrition. 2016 Apr;70(4):437-44.

25. N.N Ambadekar Risk factors for severe acute malnutrition in under-five children: a casecontrol study in a rural part of India. Indian Pediatr. 2017 Oct 15;54(10):817-824. Epub 2017 Jul 11.

26. Awoke A, Ayana M, Gualu T. Determinants of severe acute malnutrition among under five children in rural Enebsie Sarmidr District, East Gojjam Zone, North West Ethiopia, 2016. BMC nutrition. 2018 Dec 1;4(1):4.

27. Costa ME, Trumble B, Kaplan H, Gurven MD. Child nutritional status among births exceeding ideal family size in a high fertility population. Maternal \& child nutrition. 2018 Oct;14(4):e12625. 28. Wasihun AG, et al. (2018) Risk factors for diarrhoea and malnutrition among children under the age of 5 years in the Tigray Region of Northern Ethiopia. PLoS ONE 13(11): e0207743. https://doi.org/10.1371/journal. pone.020774.

29. Deribew A, Alemseged F, Tessema F, Sena L, Birhanu Z, Zeynudin A, Sudhakar M, Abdo N, Deribe K, Biadgilign S. Malaria and under-nutrition: a community based study among underfive children at risk of malaria, south-west Ethiopia. PLos one. 2010 May 21;5(5):e10775.

30. Frozanfar MK, Yoshida Y, Yamamoto E, Reyer JA, Dalil S, Rahimzad AD, Hamajima N. Acute malnutrition among under-five children in Faryab, Afghanistan: prevalence and causes. Nagoya journal of medical science. 2016 Feb;78(1):41.

31. Motbainor A, Taye A. Wasting in under five children is significantly varied between rice producing and non-producing households of Libokemkem district, Amhara region, Ethiopia. BMC pediatrics. 2019 Dec 1;19(1):300.

32. Gebre A, Reddy PS, Mulugeta A, Sedik Y, Kahssay M. Prevalence of malnutrition and associated factors among under-five children in pastoral communities of afar regional state, Northeast Ethiopia: a community-based cross-sectional study. Journal of nutrition and metabolism. 2019 Jun 2;2019.

33. Abebe Z, Haki GD, Baye K. Simulated effects of home fortification of complementary foods with micronutrient powders on risk of inadequate and excessive intakes in West Gojjam, Ethiopia. Maternal \& child nutrition. 2018 Jan;14(1):e12443.

34. Boah M, Azupogo F, Amporfro DA, Abada LA. The epidemiology of undernutrition and its determinants in children under five years in Ghana. Plos one. 2019 Jul 31;14(7):e0219665. 35. Abate $\mathrm{KH}$, Belachew T. Care and not wealth is a predictor of wasting and stunting of 'The Coffee Kids' of Jimma Zone, southwest Ethiopia. Nutrition and health. 2017 Sep;23(3):193-202.

36. Mohammed Feyisso Shaka1 et al(2020). Determinants of undernutrition among children under five years old in southern Ethiopia: does pregnancy intention matter? A community-based unmatched case control study: 20:101 https://doi.org/10.1186/s12887-020-2004-7

37. Worku T, Gonete KA, Muhammad EA, Atnafu A. Sustainable under nutrition reduction program and dietary diversity among children's aged 6-23 months, Northwest Ethiopia: Comparative cross-sectional study. International Journal for Equity in Health. 2020 Dec 1;19(1):14. 
38. Khan S, Zaheer S, Safdar NF. Determinants of stunting, underweight and wasting among children< 5 years of age: evidence from 2012-2013 Pakistan demographic and health survey. BMC Public Health. 2019 Dec 1;19(1):358.

39. Coates J, Swindale A, Bilinsky P. Food and Nutrition Technical Assistance Project (FANTA): Household Food Insecurity Access Scale (HFIAS) for Measurement of Food Access: Indicator Guide (v. 3). Washington, DC: Food and Nutrition Technical Assistance Project; 2007.

40. FMOH E. Protocol for the management of severe acute malnutrition. Federal Ministry of Health: Addis Ababa. 2019.

41. Demissie S, Worku A. Magnitude and factors associated with malnutrition in children 6-59 months of age in pastoral community of Dollo Ado district, Somali region, Ethiopia. Sci J Public Health. 2013;1(4):175-83.

42. Fentaw R, Bogale A, Abebaw D. Prevalence of child malnutrition in agro-pastoral households in Afar Regional State of Ethiopia. Nutrition Research and Practice. 2013 Apr $1 ; 7(2): 122-31$.

43. McDonald CM, McLean J, Kroeun H, Talukder A, Lynd LD, Green TJ. Household food insecurity and dietary diversity as correlates of maternal and child undernutrition in rural Cambodia. European Journal of Clinical Nutrition. 2015 Feb;69(2):242-6.

44. Khamis AG, Mwanri AW, Ntwenya JE, Kreppel K. The influence of dietary diversity on the nutritional status of children between 6 and 23 months of age in Tanzania. BMC pediatrics. 2019 Dec 1;19(1):518. 


\section{Figures}

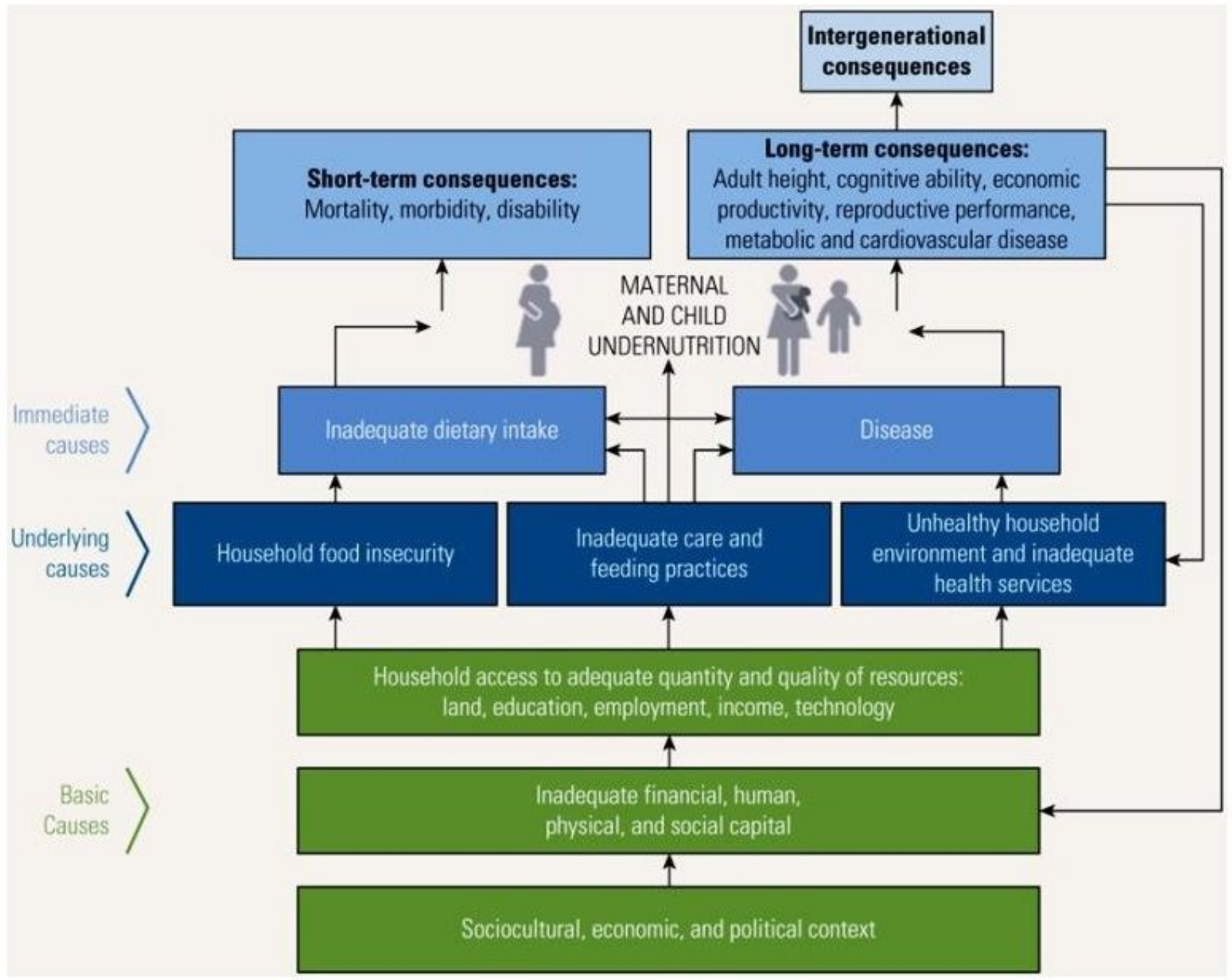

Figure 1

Conceptual framework of determinants of undernutrition (UNICEF, 2013) 


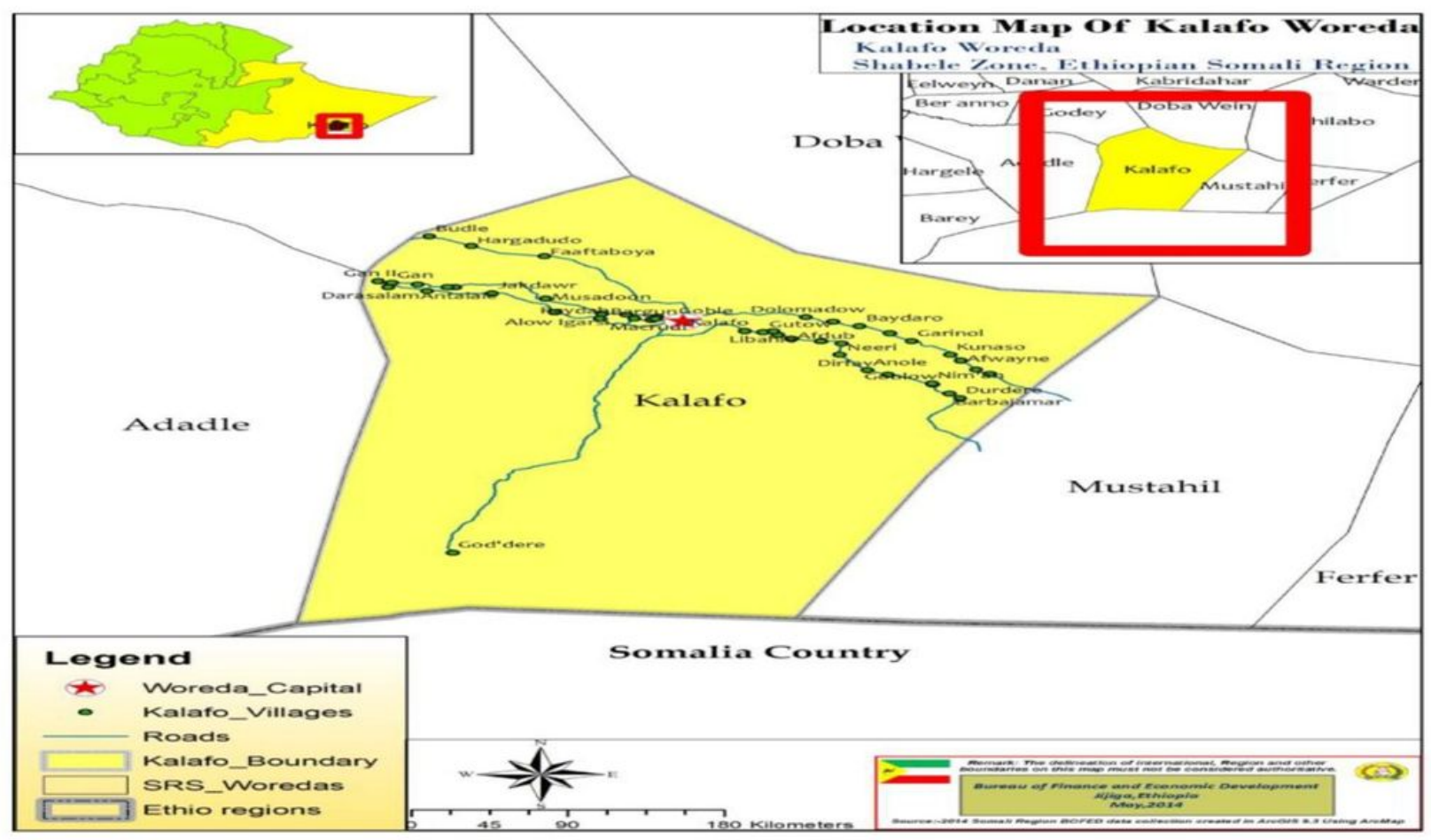

\section{Figure 1}

Location Map of Kalafo district, Somali region, Ethiopia. Note: The designations employed and the presentation of the material on this map do not imply the expression of any opinion whatsoever on the part of Research Square concerning the legal status of any country, territory, city or area or of its authorities, or concerning the delimitation of its frontiers or boundaries. This map has been provided by the authors. 